\title{
Automated field detection of rock fracturing, microclimate, and diurnal rock temperature and strain fields
}

\author{
K. Warren ${ }^{1}$, M.-C. Eppes ${ }^{2}$, S. Swami ${ }^{3}$, J. Garbini ${ }^{1}$, and J. Putkonen ${ }^{4}$ \\ ${ }^{1}$ UNC Charlotte, Civil and Environmental Engineering Department, 9201 University City Boulevard, \\ Charlotte, NC 28223-0001, USA \\ ${ }^{2}$ UNC Charlotte, Department of Geography and Earth Sciences, 9201 University City Boulevard, \\ Charlotte, NC 28223-0001, USA \\ ${ }^{3}$ UNC Charlotte, Department of Electrical and Computing Engineering, 9201 University City Boulevard, \\ Charlotte, NC 28223-0001, USA \\ ${ }^{4}$ Harold Hamm School of Geology and Geological Engineering, 101 Leonard Hall, 81 Cornell St. - Stop 8358, \\ University of North Dakota, Grand Forks, ND 58202-8358, USA
}

Correspondence to: M.-C. Eppes (meppes@uncc.edu)

Received: 4 April 2013 - Published in Geosci. Instrum. Method. Data Syst. Discuss.: 2 July 2013

Revised: 10 October 2013 - Accepted: 18 October 2013 - Published: 27 November 2013

\begin{abstract}
The rates and processes that lead to non-tectonic rock fracture on Earth's surface are widely debated but poorly understood. Few, if any, studies have made the direct observations of rock fracturing under natural conditions that are necessary to directly address this problem. An instrumentation design that enables concurrent high spatial and temporal monitoring resolution of (1) diurnal environmental conditions of a natural boulder and its surroundings in addition to (2) the fracturing of that boulder under natural full-sun exposure is described herein. The surface of a fluvially transported granite boulder was instrumented with (1) six acoustic emission (AE) sensors that record micro-crack associated, elastic wave-generated activity within the three-dimensional space of the boulder, (2) eight rectangular rosette foil strain gages to measure surface strain, (3) eight thermocouples to measure surface temperature, and (4) one surface moisture sensor. Additionally, a soil moisture probe and a full weather station that measures ambient temperature, relative humidity, wind speed, wind direction, barometric pressure, insolation, and precipitation were installed adjacent to the test boulder. AE activity was continuously monitored by one logger while all other variables were acquired by a separate logger every $60 \mathrm{~s}$. The protocols associated with the instrumentation, data acquisition, and analysis are discussed in detail. During the first four months, the deployed boulder experienced almost $12000 \mathrm{AE}$ events, the majority of which occur
\end{abstract}

in the afternoon when temperatures are decreasing. This paper presents preliminary data that illustrates data validity and typical patterns and behaviors observed. This system offers the potential to (1) obtain an unprecedented record of the natural conditions under which rocks fracture and (2) decipher the mechanical processes that lead to rock fracture at a variety of temporal scales under a range of natural conditions.

\section{Introduction}

The physical breakdown of natural building materials made of rock is a widespread occurrence that leads to great expense as well as safety concerns (e.g., Turkington, 2005), yet one of the primary processes that degrade rock (i.e., mechanical rock weathering by exposure to diurnal and seasonal cycles) is poorly understood. The importance of moisture (e.g., Hall and Hall, 1996; Nicholson, 2001), salts (e.g., Amit et al., 1993), and exposure to diurnal insolation (e.g., Blackwelder, 1933; Hall, 1999; Moores et al., 2008) in fracturing rock has been debated extensively. Although individual mechanisms of physical weathering have been addressed through field studies (e.g., McFadden et al., 2005; Eppes et al., 2010), numerical modeling (e.g., Tanigawa and Takeuti, 1983; Moores et al., 2008), and experimentation (e.g., McKay et al., 2009; Molaro and McKay, 2010), no study has collected the data 
required to demonstrate an unequivocal correlation between environmental factors and rock fracturing. Such correlations are necessary to decode processes responsible for rock fracture, and to calculate them, one would need a simultaneous record of both fracturing and the environmental conditions of the rock at the time that the fracture occurred. For example, if freeze-thaw is the primary driver of rock fracture, there should be a temporal correlation between the time that fracturing occurs and the time that the temperature of the rock drops below freezing. If directional insolation (McFadden et al., 2005) is driving rock fracture, there should be a spatial and temporal correlation between patterns of temperature driven strain and fracturing on the rock. An experimental configuration capable of monitoring rock fracturing in such a way would be useful to a wide range of researchers trying to unravel mechanisms and rates of mechanical weathering in rock.

There are a variety of tested technologies available to monitor the surface conditions of a rock mass. Monitoring when and where a fracture initiates or propagates is of primary importance when deciphering the conditions under which rock fracturing occurs. Acoustic emission (AE) systems can detect the noise related to elastic stress waves that form from the sudden release of stored elastic strain due to the initiation and propagation of fractures in a solid material. The majority of mechanisms that produce acoustic emissions in natural materials are a result of physical damage to the material such as micro-crack initiation/propagation or intergranular motion (e.g., Lockner et al., 1991). AE systems have been employed in engineering and geophysical applications to monitor fracturing under loading with good success (e.g., Eberheart et al., 1998). The monitoring of rock fractures using such devices under more natural, no-load conditions has also provided intriguing results, but this work is less common and inconclusive at this point (e.g., Hallet et al., 1991; Girard et al., 2012). Previous studies have employed a single AE sensor on a test specimen and/or used the frequency of hits recorded by that sensor as a proxy for when fracturing occurs. Recent AE technology and software enables a researcher to identify the magnitude and location of an AE "event" using multiple sensors, more clearly differentiating the AE events from background noise.

Instrumentation studies of diurnal variations in rock surface strain and/or temperature (while somewhat more common) have been limited to relatively short monitoring periods consisting of only one or two days (e.g., Hall and André, 2003; McKay et al., 2009); long periods between individual measurements (e.g., Wegmann and Gudmunson, 1999; Viles, 2005; McFadden et al., 2005), and/or only a single sensor per rock (e.g., Viles and Goudie, 2007). A long-term, multi-sensor study with high temporal and spatial measurements of temperature, strain, moisture, and acoustic emissions is unprecedented, but necessary to capture natural, spatial and temporal patterns of pertinent rock surface and environmental conditions that are associated with fracturing. The authors are not aware of another system that has been deployed matching these criteria.

The goal of this study is to develop an instrumentation plan that will monitor AE activity simultaneously with a spatially dense array of sensors that measure temperature, strain, and moisture to determine when and where fracturing occurs with respect to natural environmental conditions experienced by a rock. While there is a specific interest in examining fracturing in naturally occurring surface clasts for this study, this system can also be applied to bedrock outcrops or to building stone slabs. Ultimately, the instrumentation configuration can be employed by others to address a variety of physical weathering hypotheses related to rock fracture. The following sections describe the test configuration and the preliminary data associated with this research initiative.

\section{Test specimen description and location}

The purpose of the study is to develop protocol for a rock fracturing monitoring system for natural stone. We recognize that using natural stone potentially introduces complications in the instrumentation process, but concluded that the potential payoff of success with a natural rock as opposed to a modified natural stone or a manufactured stone was worth the complication. Currently, three different test specimens have been instrumented and evaluated successfully. The test boulder described herein is a granite boulder (Fig. 1) collected from an active gravel bar in the Santa Ana Wash in Southern California $\left(34^{\circ} 06^{\prime} 04^{\prime \prime} \mathrm{N}, 117^{\circ} 06^{\prime} 18^{\prime \prime} \mathrm{W}\right)$; hereafter referred to as "the boulder" or "the test specimen". The boulder is ellipsoid in shape with maximum dimensions equal to $340 \mathrm{~mm}$ in length, $250 \mathrm{~mm}$ in width, and $240 \mathrm{~mm}$ in height. An attempt was made to collect a boulder with as few visible fractures on the surface as possible. However, there is a vertical dimple on the examined rock (Fig. 1b). The boulder was collected from a dry wash in a semi-arid environment assuming that such a clast would be episodically tumbled in the channel, causing breaking along any major inherited fracture, while remaining relatively dry. The boulder is a hornblende-biotite granodiorite likely from Cretaceous granodiorite of Angel Oakes (Morton and Miller, 2003). It is coarse-grained (average grain diameter $1-5 \mathrm{~mm}$ ), nonfoliate, and nonporphyritic. Granite was chosen as a rock type to minimize complications due to heterogeneities such as bedding or foliation. The boulder was stored out in the open in a typical campus laboratory for approximately one year prior to deployment in the field.

The instrumentation described in the following sections was designed and developed to monitor long-term surface strain, surface temperature, surface moisture, and AE activity on the natural boulder under natural conditions. The boulder was deployed to a field site located in Gaston County, NC $\left(35^{\circ} 17^{\prime} 55^{\prime \prime} \mathrm{N}, 81^{\circ} 05^{\prime} 17^{\prime \prime} \mathrm{W}\right.$, elevation $\left.235 \mathrm{~m}\right)$ as displayed in Fig. 2. A full weather station and a soil temperature probe 

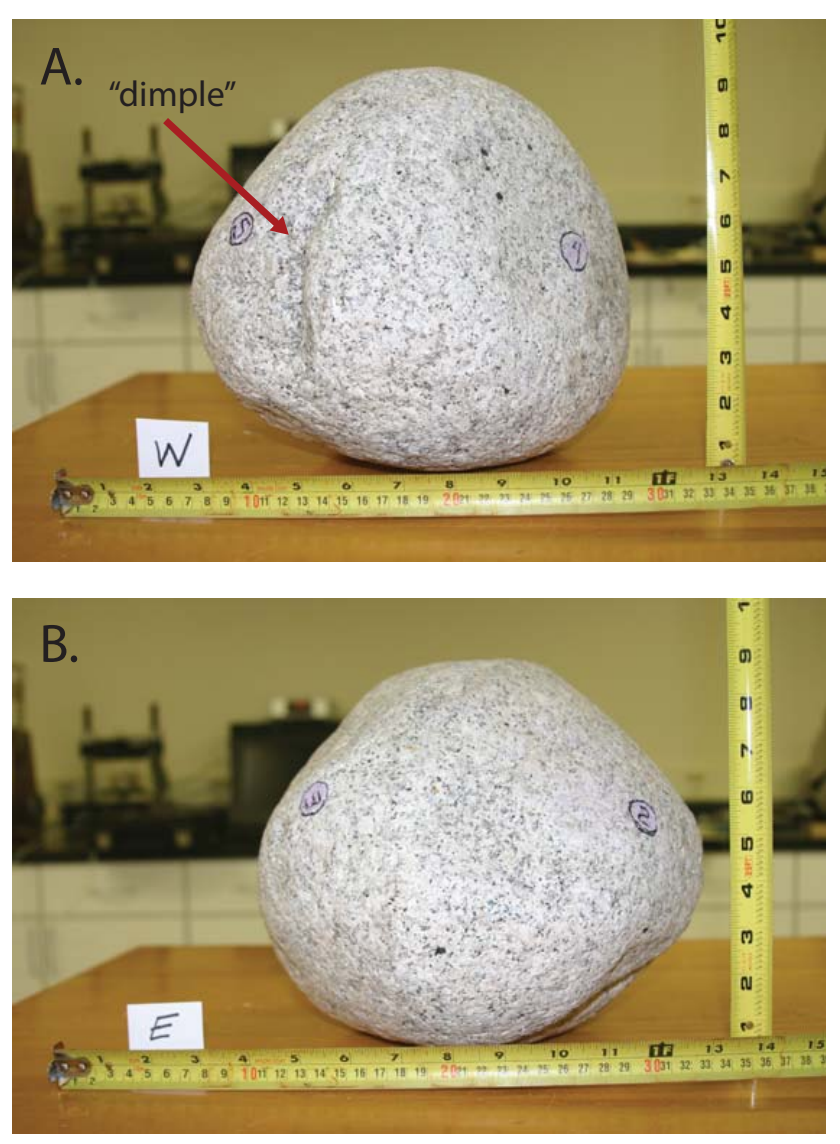

Fig. 1. Photographs of two different views of the granite boulder selected to be the test specimen for the instrumentation campaign described in this study.

were also installed at the site to simultaneously monitor the ambient environmental conditions experienced by the boulder. The following sections describe each component of the instrumentation and data acquisition configuration. The instrumentation system was improved over the course of three years and three different test specimens. We describe the configuration in sufficient detail so that the actual installation can be duplicated by future researchers.

\section{Measurement of strain}

Foil strain gage selection is dependent upon the application and the ability to determine the orientation of the principle axis during a measurement. For this study, we chose a Vishay Micro-Measurements rectangular rosette consisting of three strain gages oriented $45^{\circ}$ to one another. The rectangular rosette used for this project is a universal, general-purpose foil strain gage with a constantan grid that is encapsulated in polyimide. Because that rectangular rosette utilized in this project (Fig. 2d) utilizes a "planar" construction method (i.e., the three foil gages lie side by side rather than on top of each other), the entire gage area is thinner and more flexible, which is better for curved surfaces (e.g., small boulders). Additionally, a "planar" configuration provides for better heat dissipation, more freedom in lead wire routing and attachment, and is available in most (if not all) gage configurations and lengths. A rosette that stacks all three gages on top of each other is best utilized when the surface area on the test specimen is limited and/or when there is a steep strain gradient that exists over a short length on the test surface (Vishay Micro-Measurements, 2005).

For this field application, it was important to (1) measure the strain at multiple select locations on a relatively small boulder ( $\sim 25 \mathrm{~cm}$ diameter), (2) minimize the surface area covered by the gage, and (3) ensure an excellent electrical connection capable of withstanding harsh environmental field conditions. The backing of the gage measured $12.7 \mathrm{~mm}$ by $19.3 \mathrm{~mm}$, and each of the three foil gages measured $3.05 \mathrm{~mm}$ by $6.35 \mathrm{~mm}$. A $\sim 6 \mathrm{~mm}$ length gage ensured that each gage would span a minimum of two individual mineral crystals, given the $5 \mathrm{~mm}$ maximum grain size of the boulder in this application. The authors do not recommend a smaller gage for a boulder of this size due to the difficulties associated with wiring small soldering tabs. A $350 \Omega$ resistance gage was selected to reduce the required power and the amount of heat generated. A $350 \Omega$ resistance gage also decreases lead wire effects including circuit desensitization due to lead wire resistance and unwanted signal variations caused by lead wire resistance changes with temperature fluctuations.

Upon installation, the surface of each foil strain gage must be in full contact with the test specimen to ensure surface strain is properly evaluated. Initially, the manufacturer recommended using a minimal amount of an adhesive resin to fill in the natural gaps in the rock surface while allowing high points on the rock surface to peak through before attaching the gage with a second adhesive application. We tried this procedure on a prior test specimen, but too much of the filler adhesive was needed to create a smooth foundation for the gage and it became apparent that the gage would be measuring the deformation of the adhesive rather than the temperature dependent strains experienced by the rock. Instead, to ensure excellent contact between gage and rock, the surface was lightly sanded at each strain measurement location using a handheld Dremel tool with a light sanding wheel attachment. On a piece of the same granite, we made thin-section cross-sections of a sanded and unsanded surface and noted no difference in inter- or intra-granular fractures present at the surface on the prepared and non-prepared surface under 40x magnification. From this slide evaluation, it was determined that the light sanding did not significantly alter the surface of the rock, at least at the macroscale. M-Bond AE-10 adhesive (manufactured by Vishay Micro-Measurement) was used to bond the gage to the prepared surface using standard strain gage installation techniques (Vishay Micro-Measurements, 2005). Normally, a weight is placed on a foil strain gage 


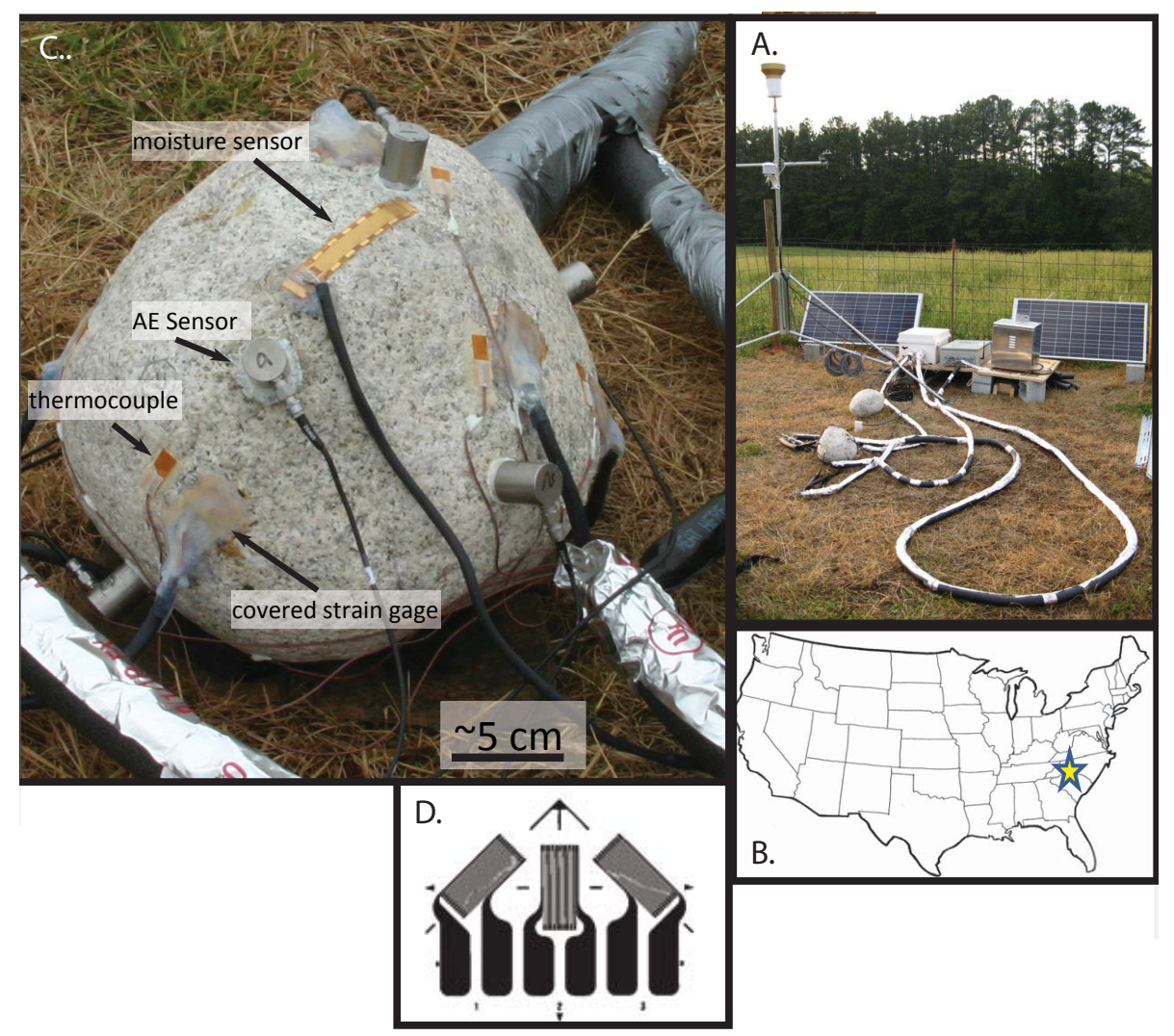

Fig. 2. (A) Photograph of the final instrumentation array and (B) map of the final deployment location for the boulder. (C) Close-up photograph of the instrumented boulder on site. (D) Diagram of strain rosettes used in this study.

attached to a flat surface to ensure there is adequate and uniform contact between the surfaces while the adhesive cures. Because of the rounded shape, it was impractical to apply a standard weight to the gage in the same way, so each gage was covered with a thick piece of silicone rubber and truck straps were tightened over this rubber to apply an adequate, uniform pressure around the boulder.

The installation orientation of a rectangular rosette foil strain gage does not matter as long as the orientation of gage 1 on the rosette is determined with respect to a known axis. The direction of gage 1 for all eight foil strain gages was measured with respect to the north-south axis established on the boulder (further described below).

A durable environmental protection layer was applied to each gage to ensure the long-term electrical integrity of the gage in the field (Fig. 2c). To accomplish this task, a layer of masking tape was applied to the boulder to create a boundary area surrounding the gage and the head of the lead wires. At the recommendation of the manufacturer, a paintbrush was used to coat the inside area with hot wax to ensure the environmental protection was able to surround the wires and fill in all tight spaces. To provide an extra layer of durability, the environmental protection was further covered in a layer of clear, RTV silicone adhesive (Dow Corning 3140), specifically designed to waterproof electrical applications.

The rock was instrumented with a total of eight rectangular rosettes (24 individual strain gages) to maximize the spatial coverage on the rock while minimizing the overall shading effects of the wires and gages. The exact placement locations for the rosettes were selected based on azimuthal direction and the availability of a natural, relatively smooth and flat surface on the test specimen. More specifically, the most stable orientation for the rock positioned in the field was determined before assigning a level "equator" around it. Subsequently, the north-south and east-west axes were established on the rock, which would ultimately be aligned with the geographic north, south, east and west in the field. Using this grid system, the gages were placed (1) on the top, (2) on the bottom, on the equator, positioned on the (3) north, (4) east, (5) south and (6) west sides of the rock, and (7) on the northeast and the (8) southwest quadrants of the rock between the equator and the top and bottom of the specimen, respectively. The orientation of each rosette was selected to ensure that cables were efficiently oriented to minimize surface coverage (attached wires would lead down instead of across the boulder). There was no attempt to place the strain gages on particular minerals or in particular orientations. However, we 
did attempt to document their orientations relative to our grid system by horizontally projecting both the grid lines and the gage 1 line while measuring the angle between them with a protractor.

The equations required to calculate principal strains from a rectangular rosette that contains three independent measurement grids are derived from a strain-transformation relationship, which expresses the normal strain in any direction on the surface of a test specimen $\left(\varepsilon_{\theta}\right)$ in terms of two principal strains $\left(\varepsilon_{P}\right.$ and $\left.\varepsilon_{Q}\right)$ and the angle $(\theta)$ from the major principal axis to the direction of the specified strain. The normal strain at any angle $(\theta)$ from the major principal axis can be calculated using Eq. (1) and Mohr's circle.

$\varepsilon_{\theta}=\frac{\left(\varepsilon_{P}+\varepsilon_{Q}\right)}{2}+\frac{\left(\varepsilon_{P}-\varepsilon_{Q}\right)}{2} \cos (2 \sigma)$

Assuming that measurement grid 1 in Fig. 2 d is positioned $\theta$ degrees from the major principal axis, measurement grids 2 and 3 are positioned at $\theta+45^{\circ}$ and $\theta+90^{\circ}$, respectively, from the major principal axis. These angles can be substituted into Eq. (1) to calculate the strain value for measurement grids 1, 2, and 3 as displayed in Eqs. (2)-(4) below.

$$
\begin{aligned}
& \varepsilon_{1}=\frac{\left(\varepsilon_{P}+\varepsilon_{Q}\right)}{2}+\frac{\left(\varepsilon_{P}-\varepsilon_{Q}\right)}{2} \cos (2 \theta), \\
& \varepsilon_{2}=\frac{\left(\varepsilon_{P}+\varepsilon_{Q}\right)}{2}+\frac{\left(\varepsilon_{P}-\varepsilon_{Q}\right)}{2} \cos \left(2\left(\theta+45^{\circ}\right)\right), \\
& \varepsilon_{3}=\frac{\left(\varepsilon_{P}+\varepsilon_{Q}\right)}{2}+\frac{\left(\varepsilon_{P}-\varepsilon_{Q}\right)}{2} \cos \left(2\left(\theta+90^{\circ}\right)\right)
\end{aligned}
$$

While $\theta$ and the major and minor principal strains are unknown, the measurement grid strains $\left(\varepsilon_{1}, \varepsilon_{2}\right.$, and $\left.\varepsilon_{3}\right)$ are calculated from the voltage measurements acquired by the data acquisition logger. Foil strain gages are resistance gages. By supplying a precise, known voltage to a resistive circuit (i.e., the foil strain gage) and measuring the return voltage, the resistance is calculated and then converted to engineering units of strain using the gage calibration factor, which can then be utilized in Eqs. (2)-(4). Therefore, Equations 2, 3, and 4 can be solved simultaneously to determine the three unknowns $\left(\varepsilon_{P}, \varepsilon_{Q}\right.$, and $\left.\theta\right)$. Equations (5) and (6) display $\varepsilon_{P}, \varepsilon_{Q}$, and $\theta$, respectively. It is important to note that the angle, $\theta$, represents the acute angle from the principal axis to the reference grid (clockwise rotation).

$$
\begin{aligned}
& \varepsilon_{P}=\frac{\left(\varepsilon_{1}+\varepsilon_{3}\right)}{\sqrt{2}} \sqrt{\left(\varepsilon_{1}-\varepsilon_{2}\right)^{2}+\left(\left(\varepsilon_{2}-\varepsilon_{3}\right)^{2}\right)} \\
& \varepsilon_{Q}=\frac{\left(\varepsilon_{1}+\varepsilon_{3}\right)}{2}-\frac{1}{\sqrt{2}} \sqrt{\left(\varepsilon_{1}-\varepsilon_{2}\right)^{2}+\left(\left(\varepsilon_{2}-\varepsilon_{3}\right)^{2}\right)} \\
& \theta=\frac{1}{2} \tan ^{-1}\left(\frac{\varepsilon_{1}-2 \varepsilon_{2}+\varepsilon_{3}}{\varepsilon_{1}-\varepsilon_{2}}\right)
\end{aligned}
$$

It is important to note that because the selected boulder is rounded, there is notable potential error in the calculations of absolute strain. The mathematics associated with foil strain gage calculations assume the gage is attached to a flat, smooth surface that extends infinitely in all directions. Therefore, the strains calculated during this project cannot be viewed as measurements of true strain on the test specimen. However, the relative values of the magnitude and direction (tension versus compression) at each measurement location can be compared to the other gages and should provide meaningful information about the state of strain across the boulder surface. In order to validate that the foil strain gage measurements were properly acquired by the hardware and accurately manipulated by the software, data collected by the CR 1000 logger using a strain gage installed on a separate surface were compared to an independent vibrating wire strain gage on the same surface (read by a Geokon GK404 readout box) during a laboratory compression test. The foil strain gage data closely matched the vibrating wire strain gage data with an $R^{2}$ value of 0.98 .

Because strain is calculated relative to prescribed antecedent conditions, foil strain gage baseline readings must be measured under constant environmental conditions (at room temperature) prior to field deployment. Strain gage data were measured for all 24 gages by the data acquisition system while the test specimen was located in a laboratory environment at a constant room temperature. Since mechanical and temperature induced strain will not vary under these controlled conditions, the average strain value for each gage was calculated, inputted into the software program, and used as a reference measurement for all strain data moving forward.

\section{Measurement of surface temperature}

A standard T-type thermocouple (Omega SA1XL-T-120) with a copper-constantan junction was utilized for this project (Fig. 2c). Due to the durability, repeatability, and responsiveness of this temperature measurement sensor, it is widely used and accepted in a variety of engineering field studies that require measurement of surface temperature on various materials. The stated accuracy of this sensor $\left( \pm 1^{\circ} \mathrm{C}\right)$ is adequate for this analysis and is capable of functioning in temperatures ranging from -200 to $350^{\circ} \mathrm{C}$. A cement adhesive (Omegabond 400) was used to attach all thermocouples to the rock test specimen following manufacturer's instructions.

One thermocouple was installed adjacent to each strain gage to allow simultaneous recording of strain and temperature across the test specimen. To verify that the exposed thermocouples were not adversely affected by direct short wave radiation, a simple shading experiment was conducted in the field. On a cloudless, cold day (air temperature $\sim 5^{\circ} \mathrm{C}$ ), each of the sunlit thermocouples were shaded for 3-4 min with an aluminum foil disc $\left(1 \mathrm{~cm}^{2}\right.$ area) held at a distance, approximately $20 \mathrm{~cm}$ from the rock surface. The cold air temperature and the lack of clouds ensured that both the diffuse and down-welling long wave radiation were at a minimum. 
The temperature differences that we recorded between full sun and shaded conditions ranged from 1.1 to $1.4^{\circ} \mathrm{C}$. Thus, it was concluded that the direct radiation induced temperature error on the thermocouples is relatively small and that daily highs render them only slightly warmer than the actual surface temperature.

\section{Measurement of acoustic emissions}

Acoustic emissions are defined as transient elastic waves generated by the rapid release of strain energy or by the sudden redistribution of stress within a material. The majority of sources of acoustic emission activity in rock are attributed to damage-related deformation such as the initiation and propagation of micro-fractures, and plastic deformation (Rao et al., 1999; Lei et al., 2000; Khair, 1984). The purpose of an $\mathrm{AE}$ sensor (also referred to as a piezoelectric transducer) is to convert the mechanical energy carried by an elastic wave into an electrical signal. An adhesive couplant must be used to attach the gage while ensuring that voids do not exist between the specimen and sensor.

The frequency, sensitivity, size, and temperature capability of commercially available sensors were evaluated as part of the sensor selection process. The sustainability of the equipment and sensors in a natural, outdoor environment was also important for this field-based project. A moderate frequency (100-450 kHz), pre-amplified, low power consumption sensor (Physical Acoustics Corporation PK151) was selected with the help of the manufacturer (displayed in Fig. 2c). Physical Acoustics Corporation (PAC) equipment, sensors, and software were selected for use during this project since they were the only US based company that could provide three dimensional location capability of an acoustic emission event at that time in the planning process.

The PAC SH-II data acquisition system utilizes two software programs for monitoring and analysis. The SHClient software controls all primary communications with the $\mathrm{AE}$ sensors on the rock during the calibration process and during the data collection period. It is also used to set up all initial configurations for the hardware. It is important to distinguish the difference between an $\mathrm{AE}$ "hit" and an $\mathrm{AE}$ "event". If the elastic wave measurement exceeds a pre-defined threshold value and is measured by one of the pre-amplified sensors attached to the specimen, data will be recorded and referred to as an acoustic emission "hit". If the same wave is registered by at least four sensors on the specimen, it is referred to as an AE "event". The four sensor minimum configuration was specified by the manufacturer for the calculation of location in a three dimensional domain. It also serves as a conservative method for distinguishing significant AE-producing phenomena affecting the rock. The higher the number of acoustic emission hits, the higher the associated physical damage to the rock (i.e., fracture initiation and propagation; e.g., Huang et al., 1998). Furthermore "burst" types of $\mathrm{AE}$ waveforms that have been observed in this study are associated with fracture initiation and propagation (Pollock, 1989). Pre-deployment observations determined that effects from small impacts including insects landing on the rock or small sand grains hitting the rock might register hits on one or two sensors. Therefore, rock damaging AE events are considered to be associated with $\mathrm{AE}$ events caused by activity from four sensors simultaneously measuring the same activity. It should be noted that establishing direct correlations between $\mathrm{AE}$ data and actual rock damage is a complex process (e.g., Huang et al., 1998). There is no direct way to distinguish, for example, crack initiation from crack propagation or to make a direct correlation between event signal and length of rupture. It is possible in some cases to determine the mode of cracking, but such an analysis was beyond the scope of this study.

While four sensors were the established minimum, six sensors were utilized for all future AE sensor installations, but there are several key location criteria that must be met to accurately quantify a three-dimensional location using $\mathrm{AE}$ data. It is important that (1) the locations of the sensors be arranged in a pattern that ensures no four sensors are on the same plane, (2) every combination of three AE sensors forms a triangular plane, and (3) multiple planes are as orthogonal to each other as possible. Meeting these criteria while establishing the installation locations of the sensors on any test specimen is not trivial and requires trial and error testing.

The field data collected by the SHClient software is then imported into the AEwin software to calculate the threedimensional source location of an $\mathrm{AE}$ wave. In general, $\mathrm{AE}$ source localization is determined using an arrival time that is calculated using a trial or guessed location that was derived using arrival times of individual sensors, and a user-defined velocity (see below). The guessed location is then corrected using differences between measured and calculated arrival times. The calculated arrival time can be written as

$t_{i}^{c}=t_{\left(x_{i}, y_{i}, z_{i}, x_{0}, y_{0}, z_{0}\right)}+t_{0}$.

This calculated arrival time consists of travel time $t$, which is a function of the sensor locations $\left(x_{i}, y_{i}, z_{i}\right)$, the hypocenter $\left(x_{0}, y_{0}, z_{0}\right)$, and the source time $t_{0}$. Since the equation contains four unknowns, four arrival times must be known to solve for the location. In general, the accuracy of the three dimensional location is dependent upon a number of factors including (1) the accuracy of the time-distance relationship (wave velocity) for the specific specimen, (2) the installation of an adequate number of sensors in the appropriate locations on the test specimen, and (3) the AE signal wave analysis thresholds utilized by the software. Manufacture's recommendations were utilized to determine the proper number and locations of the sensors, the AE signal wave analysis thresholds, and a method for determining a wave velocity specific to our project and test specimen. 


\subsection{Determination of wave velocity}

In general, the wave velocity material property is determined by a calibration process that involves inducing a wave on the material and calculating how fast it takes an $\mathrm{AE}$ sensor attached to the material to receive that signal, knowing the distance that the wave traveled. As a first step in the iterative calibration process, two rectangular calibration blocks were specially cut from two similar but not identical rock materials (two different granites) so that simple, square geometry (origin located at one corner of the calibration block) could be used to determine distances between each $\mathrm{AE}$ sensor installed on the calibration specimen. For a three-dimensional block or boulder, point location $(x, y$, and $z$ coordinates in a three dimensional domain) is required. The software specifications require a minimum of four sensors to provide "point" location capability, but the use of additional sensors is recommended to increase success and cover wide surface areas. It also depends upon the size of the test specimen, and this process can only be validated through trial and error.

With the sensors in position on the calibration block, an AE event was simulated using a pencil lead break (PLB) test in accordance with the American Society for Testing and Materials standard specification (ASTM E 976). Multiple PLB tests were performed adjacent to individual sensors so that the distance between that sensor and the PLB was zero. As such, the timing of the first return of the AE represents the timing of the PLB itself. Thus the travel time of the PLB event to all 5 remaining sensors could be determined by the AE system. Using the $\mathrm{x}_{i}, \mathrm{y}_{i}$, and $\mathrm{z}_{i}$ coordinates of each sensor $(i)$, the known location ( $\left.\mathrm{x}_{p l b}, \mathrm{y}_{p l b}, \mathrm{z}_{p l b}\right)$ of the PLB on the calibration block, and the time recorded $(t i)$ by the $\mathrm{AE}$ data acquisition system that it took each sensor to register the PLB activity induced on the material, the wave velocity of the granite block and be calculated:

$V_{i}=\left(\operatorname{sqrt}\left(\left(x_{i}-x_{\mathrm{plb}}\right)^{2}+\left(y_{i}-y_{\mathrm{plb}}\right)^{2}+\left(y_{i}-y_{\mathrm{plb}}\right)^{2}\right) / t_{i}\right.$.

This process was repeated at multiple locations and a statistical analysis was performed to determine the average wave velocity for this material as a starting point. For the first calibration block, the average wave velocity was determined to be $5353.501 \mathrm{~m} \mathrm{~s}^{-1}$. To validate this value, it was inputted in the software, and used to verify the location of all subsequent PLB tests. This validation exercise was performed 10 times in seven different PLB locations on the surface of the rock. The average source location calculated by AEwin was within $10.1 \mathrm{~mm}$ on average (standard deviation equal to $2.4 \mathrm{~mm}$ ) of the actual PLB location on the calibration block.

Subsequently, the same process was repeated for a second, different calibration block composed of the same granite as our final test specimen. These block tests resulted in an average wave velocity equal to $2293.2 \mathrm{~m} \mathrm{~s}^{-1}$. Ten PLB validations tests were performed for this block in six different locations, and the average source location calculated by AEwin was within $11.3 \mathrm{~mm}$ on average (standard deviation equal to $4.8 \mathrm{~mm}$ ) of the actual PLB location on the calibration block. Noting the difference in wave velocity values for two calibration blocks that were cut from similar parent rock material (two different granites), it was determined that it would be beneficial to determine wave velocity directly on the test specimen itself. The authors felt that any accuracy lost using a dimensionally complex specimen was outweighed by the benefit of making the measurement directly on the specimen.

To facilitate the consistent and accurate determination of the coordinates on a spherical test specimen, a three sided corner box was constructed, the boulder was placed inside, and the $x, y$, and $z$ coordinates were easily measured from the sides of the box to the point location of the PLB test. The origin of the coordinate system $(0,0,0)$ was located at the intersection of the three sides of the corner box. In subsequent test specimens, high resolution lidar scans were utilized to obtain more accurate surface measurements.

PLB tests were performed at various locations on the boulder, and the measured versus actual coordinates of each PLB test were compared. Initially, acceptable readings were acquired using the wave velocity from the second calibration block. In one area on the rock (near the location of the dimple displayed on Fig. 1b), however, the velocity did not give accurate results. Because that portion of the rock did not have sensors in the vicinity, the AEwin software was unable to accurately locate $\mathrm{AE}$ sources in this area. As part of the iterative, trial and error process, one sensor was moved from the bottom of the rock to the top of the dimple. The validation exercise was repeated and the difference between the measured coordinates and actual coordinates of the PLB test was reduced.

As a last step to further refine the $2293201 \mathrm{~mm} \mathrm{~s}^{-1}$ wave velocity, this value was systematically varied in magnitude as a software input $(2200000 ; 2400000 ; 2600000$; and $2800000 \mathrm{~mm} \mathrm{~s}^{-1}$ ) until the coordinates more closely converged. The best results were achieved on the boulder using an average wave velocity equal to $2400000 \mathrm{~mm} \mathrm{~s}^{-1}$. This value was inputted into the software, the validation exercise was performed 10 times in five different locations, and the average measured location calculated by AEwin was within $24.8 \mathrm{~mm}$ on average (standard deviation equal to $9.6 \mathrm{~mm}$ ) of the actual PLB location determined using the $x, y, z$ coordinate system established.

Once the locations of the sensors were confirmed, the final installation was completed using a two-part epoxy (E-20NS Loctitite Hysol Epoxy). This adhesive was recommended by the manufacturer to ensure the adhesive used for this study would provide excellent contact between material and sensor without voids between the sensor and the specimen, and would withstand the environmental conditions expected in the field. It is recommended that this epoxy cure under heat to increase the bond strength and the sensor be attached to subvertical, upward facing faces of the test specimen to prevent 
the weight of each senor from overcoming the strength of the adhesive.

\subsection{Measurement of surface moisture}

A Campbell Scientific 237F wetness sensing grid (Fig. 2c) was used to evaluate the surface moisture on the boulder in the field. This sensor is designed to measure moisture on the surface of plant materials. It consists of a flexible polyamide film circuit ( $14 \mathrm{~mm}$ by $90 \mathrm{~mm}$ ) with interlacing gold-plated copper fingers. Any condensation or rain on the sensor will lower the resistance between the copper fingers (spaced $0.25 \mathrm{~mm}$ apart to ensure a resistance change due to fine droplets). This sensor was attached to the top of the test specimen and wire solders were protected using the same MBond AE10 adhesive and RTV silicone that were used for the foil strain gages.

The levels of resistance as a function of moisture were evaluated in a controlled laboratory environment. Upon careful misting with water, sensor resistance ranged from $>0$ to $200 \mathrm{k} \Omega$ even with single droplets of water. Therefore, any reading higher than 200 was considered dry and any reading less than or equal to 200 is considered to indicate the presence of moisture.

\section{Measurement of environmental and soil conditions}

In order to monitor the micro-climate at the field site, a standard Campbell Scientific weather station capable of measuring ambient temperature, relative humidity, wind speed, wind direction, barometric pressure, insolation and precipitation (to $0.1 \mathrm{~mm}$ ) was installed on site.

Although the boulder was not embedded in the ground during this study, it was anticipated that soil moisture might affect ground surface temperature, possibly impacting the bottom temperature of the boulder. A CS616 water content reflectometer was installed to measure the volumetric water content of soil using time-domain measurement methods that are sensitive to the dielectric permittivity of any material. The calibration curve supplied by the manufacturer was verified in a controlled laboratory environment.

\section{Data acquisition configuration}

A Campbell Scientific CR1000 served as the logger for all instrumentation on the surface of the rock and adjacent to the test specimen (including the soil probe and weather station) with the exception of the AE sensors. The logger monitored the 24 strain gages via two Campbell Scientific AM16/32, 16-channel multiplexers, and it monitored the eight thermocouples via a single AM 25T, 25-channel multiplexer. The soil probe and weather station sensors were connected directly to the logger.
The main components of the PAC SH-II logger included the CPU board and two four-channel modules, which contain the analog circuitry for the system and process the analog input signals from the sensors with the use of filters and analog-digital converters. Up to eight AE sensors can be monitored using this configuration.

Both systems were enclosed in water-tight enclosures for this field application and all data was downloaded using a CDMA cellular modem that interfaced with the data logger software. McKay et al. (2009) and Hall and André (2003) noted that $>1$ measurement per minute temporal resolution of data may provide key insights into fracturing processes and the data acquisition system described herein was able to achieve that sampling frequency.

While it was possible to connect directly to both systems using either a serial cable (for the CR1000) or an Ethernet cable (for the SH-II), both systems were routinely downloaded using a CDMA technology cell-phone connection. The system was powered by two $115 \mathrm{~W}$ solar panels (Fig. 2) regulated by a Morningstar PS regulator/controller. Back-up power was provided by three additional $12 \mathrm{~V}, 116 \mathrm{Ah}$ batteries to ensure continuous power.

\section{Field deployment process}

The boulder was deployed to the middle of a cow pasture with full sun exposure located on a drainage divide in Belmont, North Carolina (Fig. 2b). For our application, it was important to locate an open site without shade from trees or structures. Additionally, it was important that the site did not have power lines in the vicinity that would generate "noise" in the AE signals. Before deployment, it was important to identify any sources of noise on site that may cause error in the $\mathrm{AE}$ data due to the sensitivity of this measurement. To determine potential sources of noise on site, raw data was collected continuously for approximately one hour using the $\mathrm{AE}$ data acquisition system and there were no hits or events during this time period. Previous rock specimens installed on campus (on roof tops or closer to mechanical equipment near buildings) and off campus in residential areas (closer to power line sources) clearly showed noise issues in the data during an equivalent noise check exercise.

The boulder was instrumented with all sensors and wired in a laboratory setting prior to deployment. The boulder and wires were transported to the field on a large pallet. The boulder and wires were then removed from the pallet at the final field site and the boulder was set directly on the ground surface, initially defoliated using a household weed killer. Prior to field deployment, a wire fence was constructed to keep cows and other large animals from interfering with the experiment. The test specimen was oriented in accordance with the north, south, east and west axes pre-determined during the sensor installation process. The $3 \mathrm{~m}$ tall tripod and steel 
mast for the weather station was constructed to the northwest of the rock to ensure minimum shading.

\section{Preliminary results and discussion}

In the course of this research, three boulders have been deployed including this one (Garbini, 2009; Eppes et al., 2012). All three boulders show similar spatial and temporal patterns in AE events, surface conditions, and microclimate. These similarities strongly suggest that the results have general validity instead of being specific to an individual boulder. The preliminary data presented herein demonstrates the data validity and showcases the overall range of spatial and temporal analyses that the data set allows.

The boulder described in this paper was monitored for 11 months (20 June 2010 through 18 May 2011) in the field. A preliminary analysis of that data set for the months of June through September 2010 is presented. During this time period, we recorded data for 92 days. Loss of data days was due to periodic power failures and a site disturbance. For these 92 days when data was complete, 11607 acoustic emission events (signal simultaneously detected by at least four transducers) and 638960 hits (signal detected by 1-3 transducers) were recorded by the $\mathrm{AE}$ data acquisition system. A linear regression correlating hit and event data yields an $R^{2}$ of 0.41 with a Pearson's $p$ value of $<0.05$. The relatively low $R^{2}$ is due to the fact that there are many days when there are hits but no events in the data set. If those days are removed, then the $R^{2}$ rises to 0.69 . Overall, there is relatively strong relationship between the time that hits and events occur, but there are a significant number of instances when hits occur unassociated with events. We interpret these results to mean that our four hit per event threshold represents a conservative yet strong proxy for the total amount of fracture damage experienced by the rock. Although it is beyond the scope of this paper, AE Win software also calculates other waveform data associated with each event. Future analyses will further differentiate damage-causing events as a function of their energy. The remainder of this discussion will focus on overall amounts, timing and locations of events.

The 11607 events occurred within 367 different time stamps (each representing a unique $60 \mathrm{~s}$ time interval) during 36 days out of 92 on record. AE events were typically recorded in temporal clusters (multiple events over the course of a few minutes time on a few specific days). For example, more than $95 \%$ of the events occurred during only $12 \%$ (11 days) of the time period. There were also patterns in the overall daily timing of events. The vast majority of all events $(96 \%)$ were recorded during the late afternoon and evening hours (between 16:00 and 23:00 LT - Eastern Standard Time). No events occurred between 03:00 and 09:00 LT (Fig. 3). Both field measurements of fracture orientations (McFadden et al., 2005; Eppes et al., 2010; Fig. 4) and numerical modeling of stress in a rounded boulder exposed to
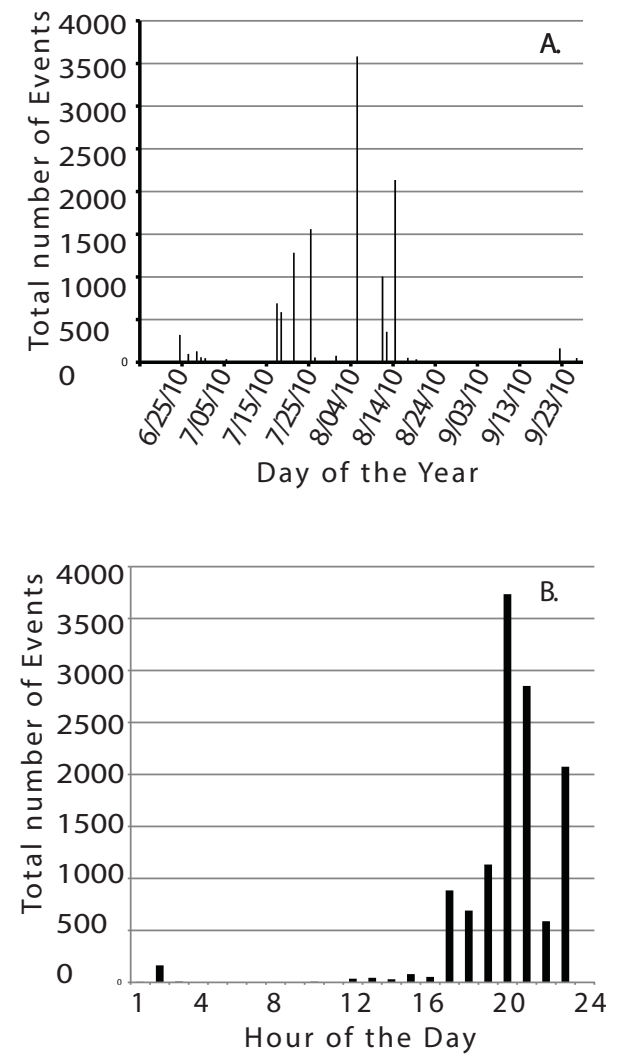

Fig. 3. Histogram of numbers of events for the time period of JuneSeptember 2010 as a function of (A) date and (B) hour of the day.

diurnal temperature changes (Shi, 2011) predict that morning might be a prominent time for rock fracturing, but these data indicate that morning is characterized by few, if any, fracture events. Thus, even this simple temporal analysis of the $\mathrm{AE}$ data set demonstrates the robustness of the data and its high potential for contributions to physical weathering research.

Rock surface and environmental data also provide key insights into the conditions under which fracturing occurs. Figure 5 displays four graphs, which depict temperature, temperature difference across the surface of the rock, select weather conditions (wind speed), and maximum principle strain as a function of time for a typical day in which events occur (26 July 2010). Additionally, the number of AE events occurring each minute of this day is depicted on the secondary axis of each graph. The graphs in Fig. 5 are representative of a typical suite of graphs automatically generated for each day of data that is collected. In general, the patterns visible in this figure are notably repeated throughout this data set and were also observed during event clusters that occurred during the monitoring periods associated with the other two test specimens previously mentioned. A more detailed comparison of all data sets will be completed for future publications.

For any given day in the data set, all rock surface temperatures typically begin to increase early morning (this increase occurs after 06:00 LT on 26 July as displayed in Fig. 5a), 


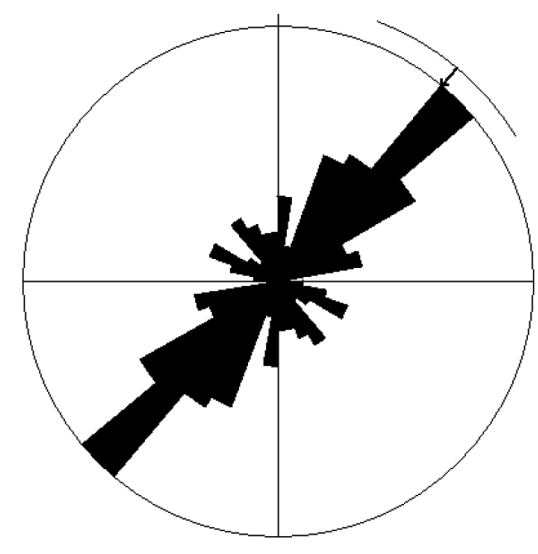

(a)

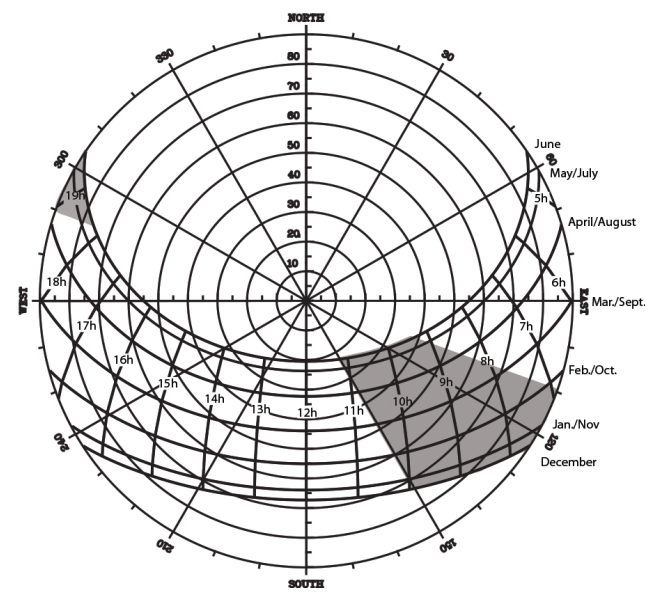

(b)

Fig. 4. Modified from Eppes et al. (2010). A. Rose diagram of measured crack orientations from 101 rocks in the Gobi Desert. Arc represents $2 \sigma$ mean resultant direction of data $\left(40^{\circ}\right.$ northeast). B. Sunpath solar path chart for the Gobi field site. Modified from a chart created through the University of Oregon Solar Radiation Monitoring Laboratory website. Shaded areas represent instances when the sun would be at a $90^{\circ}$ angle from average crack angle of $40^{\circ}$. This type of field data is exemplary of this and other studies that show that rock cracks exhibit preferred orientations (e.g., Eppes et al., 2010; McFadden et al., 2005). If cracks form perpendicular to the direction of heating and cooling, then these preferred orientations suggest that cracks form due to stresses that arise in the morning (Eppes et al., 2010).

peak early afternoon, and then decrease continuously into the evening. The timing and/or magnitude of diurnal temperature changes that we observe throughout the data set are generally consistent with other shorter-term studies of rock surface temperatures (e.g., McKay et al., 2009; Viles, 2005; Hall and André, 2003). Surface temperatures on the test specimen are consistently higher than ambient temperature, and all temperatures appear to be rapidly influenced by cloudiness (illustrated in insolation data), wind speed, and direction. The thermocouple on the rock with the highest temperature and the thermocouple with the lowest temperature recorded each minute are used to determine the maximum range in surface temperature across the boulder's surface (Fig. 5b). In general, the largest temperature range across the rock surface (almost $20^{\circ} \mathrm{C}$ ) is between the south and/or top sides of the boulder and the bottom of the boulder. On any given day, this range is relatively low until all temperatures begin to increase through the early morning in conjunction with the absolute surface and air temperature. Because this data set enables the determination of spatial and temporal variability of the temperature characteristics of the rock over an entire year, this surface temperature data set is an unprecedented opportunity to address the frequency, duration and/or magnitude of conditions that are often hypothesized to lead to fracture. Hypotheses related to processes such as freeze-thaw (e.g., the amount of time a rock is in the proposed -4 to $-15^{\circ} \mathrm{C}$ range thought to be ideal for fracturing by sustained freezing temperatures; Walder and Hallet, 1985; Hallet et al., 1991) and/or thermal shock (e.g., the hypothesized $2^{\circ} \mathrm{C} \mathrm{min}^{-1}$ threshold often cited for thermal shock fracturing; Richter and Simmons, 1974) can be directly tested with the data set.
As the air and rock surface temperatures rise on 26 July, as with most days, the measured surface strains at all locations on the test specimen increase, indicating that the test specimen surface is experiencing tensile strains as a result of elevated surface temperatures. When rock surface temperatures decrease, the rock contracts. Unexpectedly, over the course of this four month analysis, the majority of strains were positive, indicating that the rock does not return to an expected neutral state in which strains equal the background strains measured in the laboratory, even when the rock surface temperatures are the same as those recorded in the laboratory setting. Numerical modeling of simple temperature-related strain for an isotropic material predicts that a rock would return back to an unstressed state (i.e., zero strain) after the heating source is removed and the rock is allowed to equilibrate with ambient temperatures (Shi, 2011). We currently assume that differences between modeling results and our data are due to the fact that our strain gages cover a number of minerals and crystals in varying orientations. The individual thermo-mechanical properties of the different grains are likely leading to the observed permanent strain measured by our gages. For many of these data (including 26 July), there was no obvious abrupt change in strain concurrent with $\mathrm{AE}$ events. However, this would not necessarily be expected unless fracturing occurred at or very near the site of the strain gage itself. Nevertheless, these strain data and the comparison of relative strain on different sides of the rock are already providing interesting and relevant insights into the stress state of the rock as it is heated and cooled. 

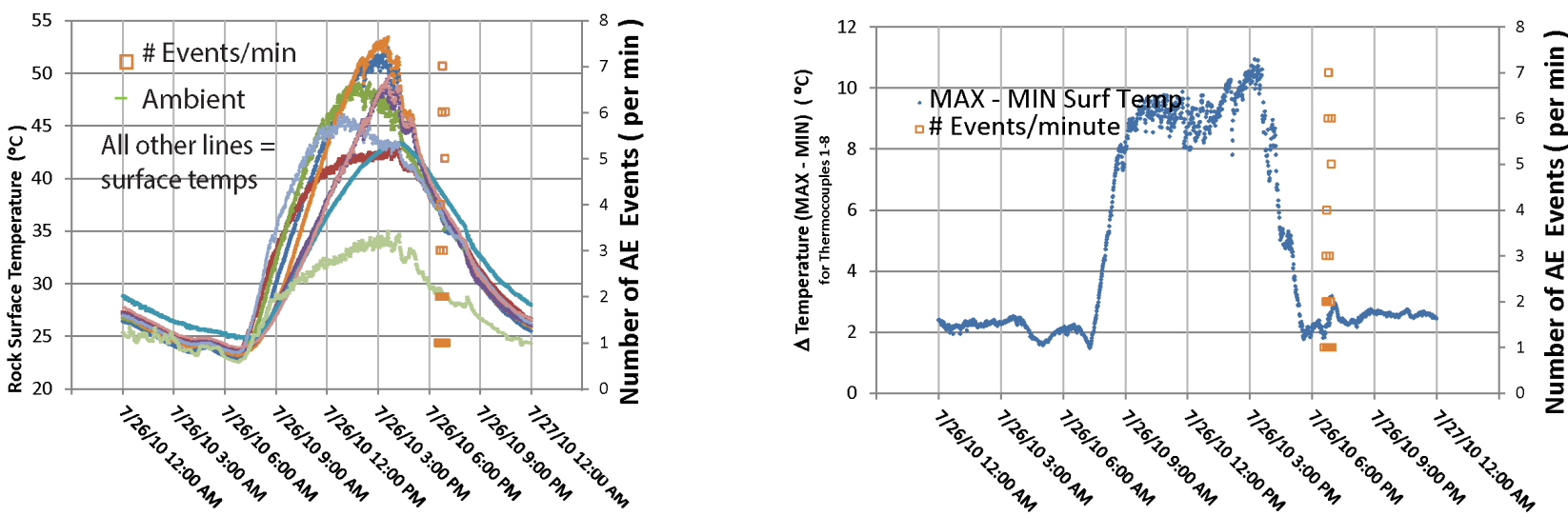

A. B.
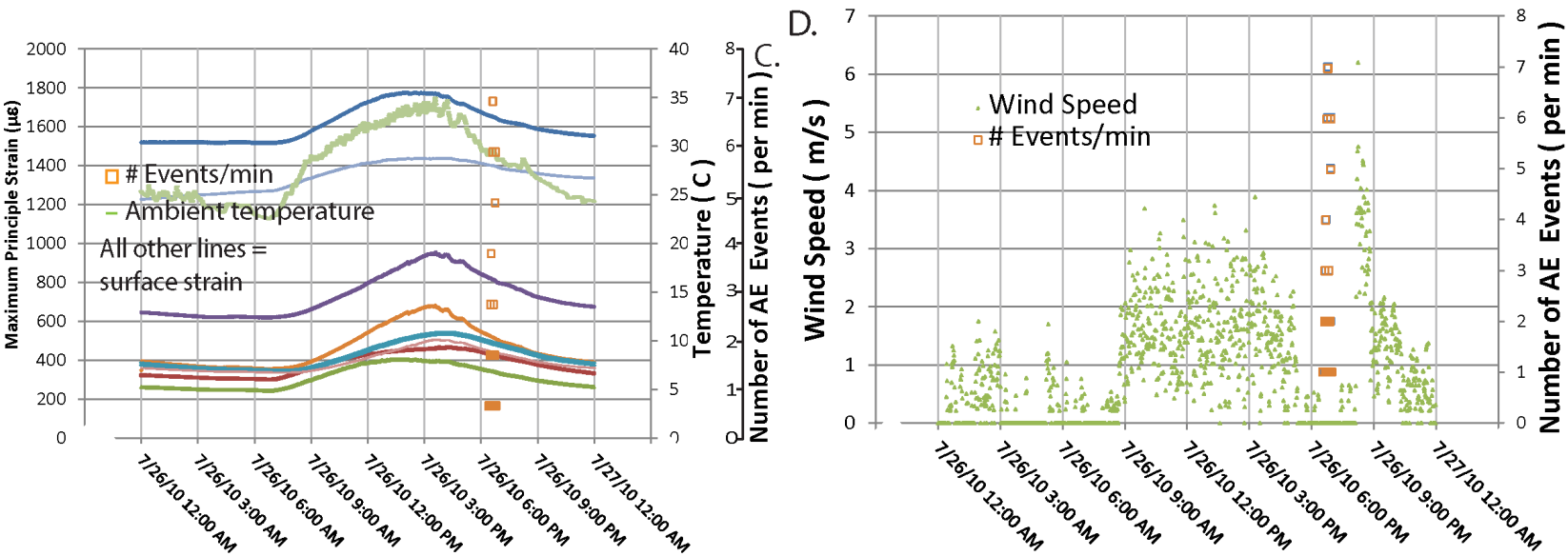

Fig. 5. Graphs of total numbers of events per minute (each orange box represents data for an individual minute) for a single day (26 July 2010) along with concurrent per minute. (A) Rock surface and ambient temperature, (B) temperature difference between the hottest and coldest thermocouple on the rock, $(\mathbf{C})$ calculated maximum principal strain for all 8 strain gages and ambient temperature, and (D) wind speed measured adjacent to the rock.

The AE events recorded on 26 July occur at approximately 18:00 LT as surface and air temperatures are in an overall state of cooling. Additionally, at the time that these events occur, there is a notable, small increase in temperature range (the difference between coolest and warmest surface temperature). The coincidence of AE events with a secondary, lateafternoon or early evening spike in rock surface temperature range was observed frequently for this boulder as well as for other boulders (Garbini, 2009; Eppes et al., 2012). The drop in wind speed (Fig. 5c) that occurs during this time period likely explains the second spike in the temperature range, where the loss of heat advection by wind would have caused the upper surface of the rock to warm up again. On most other days with major event clusters, similar abrupt changes (typically increases) in rain or wind are observed coincident with the timing of the events. Changes such as these in microclimate have been shown or hypothesized by others to lead to very rapid rock surface temperature fluctuations (McFadden et al., 2005; Molaro and McKay, 2010). This data set will enable the characterization of those weather conditions that lead to rapid change in rock surface conditions and help define a suite of conditions that correlate most strongly with $\mathrm{AE}$ events. Using long-term climate records, the potential past frequency of such conditions can then be determined. Such comparisons will allow us to (1) determine if the environmental conditions that are associated with rock fracturing are extreme compared to long-term climate, (2) use the frequency of such climate conditions in the past to infer future rates of rock fracturing relative to the period of observation, and (3) consider rates of physical weathering as a function of past climates that may have had higher prevalence of such conditions.

In addition to analyzing the temporal patterns of AE events and boulder conditions, we are also able to examine patterns in the location of $\mathrm{AE}$ events (Fig. 6). AEwin analyzes $\mathrm{AE}$ hit data to mathematically determine the three-dimensional location of all AE events (similar to using multiple seismographs to determine the focus of an earthquake). In order to 

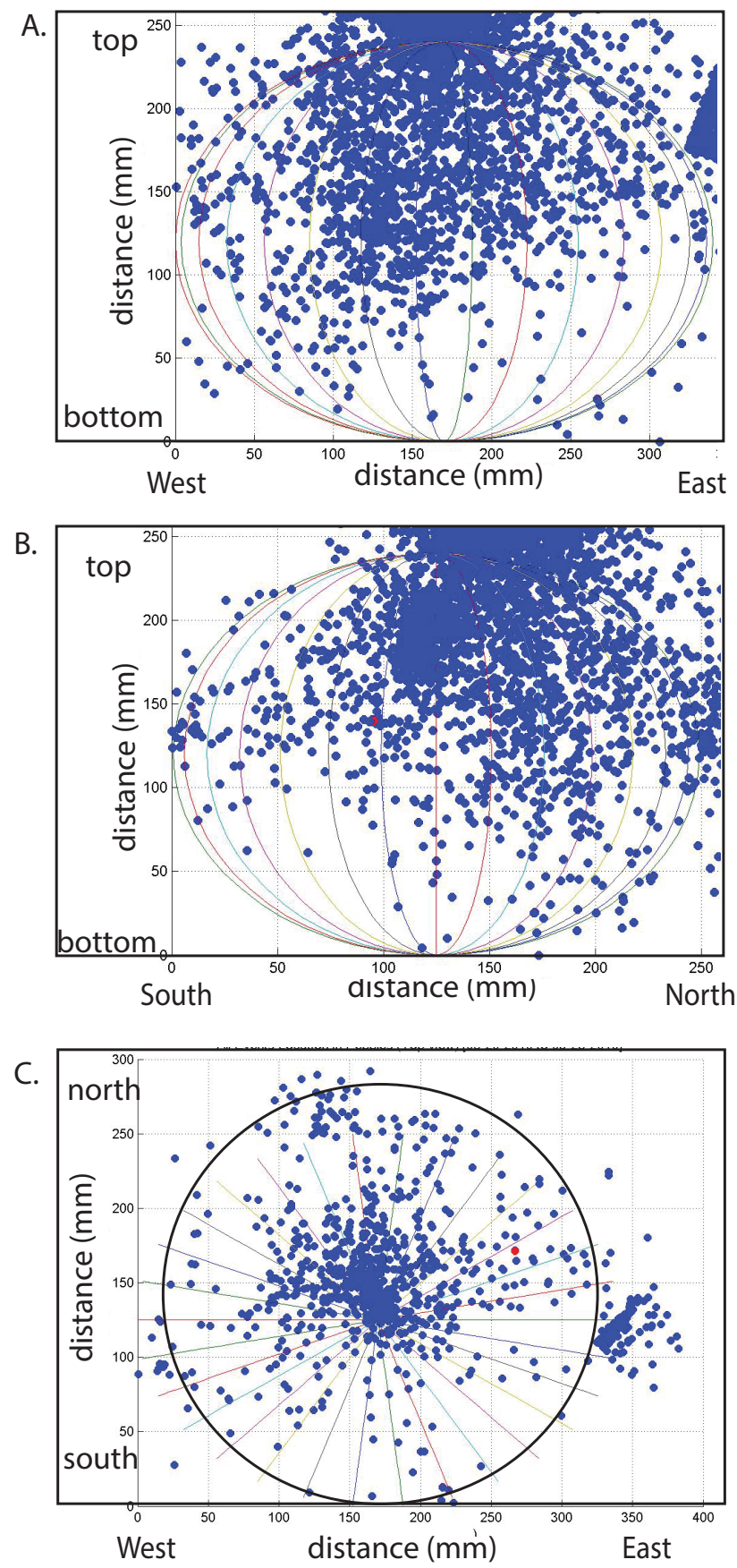

Fig. 6. Graphical representation of the location of events as calculated by AEwin software for (A) a west to east side view of the test specimen, (B) a south to north side view of the test specimen and (C) a top-down view of the test specimen. In all figures, the ellipsoid shape is an approximate location of the surface of the rock based on its maximum dimensions. The events that are plotted are those that fall within $5 \mathrm{~cm}$ of the ellipsoid shape (5051 events). visualize the locations with respect to our boulder, a threedimensional ellipsoid approximation of the exterior shell of the boulder was generated within MATLAB using the boulder's dimensions (length, width, and height). This ellipsoid was then plotted along with the calculated locations of events in an attempt to identify spatial patterns of boulder damage.

In order to focus on accurately localized events, events that fall within a $5 \mathrm{~cm}$ margin of a generalized ellipsoid the shape and size of the test specimen are targeted for analysis (Fig. 6). Although a relatively large number of events $(\sim 50 \%)$ fall outside of this region, broad clouds of data similar to this data set are the norm when localizing large amounts of AE data using automated software (e.g., Grosse and Ohtsu, 2008). In particular, a complex test specimen (i.e., natural rock) with irregular boundaries and an inhomogeneous structure causes reflections and scattered waves that interfere with the signal and the localization effort. Nevertheless, it is generally accepted that the overall density of $\mathrm{AE}$ localizations can be used as a reliable indicator of the location of a region of high $\mathrm{AE}$ activity/source within a specimen, because correct locations will be concentrated in actual areas of fracture within the rock (e.g., Grosse and Ohtsu, 2008). Furthermore, the timing and numbers of individual $\mathrm{AE}$ events associated with miss-locations have been shown to represent valid emissions due to rock damage (e.g., Grosse and Ohtsu, 2008); they are just not properly localized. Thus, overall, (1) the number of AE events represents a satisfactory proxy for relative amounts of fracture initiation and propagation and (2) the densest clouds of location data that fall within the ellipsoid can provide meaningful insight into general fracture locations.

A preliminary visual inspection of this data set shows that the majority of the events are located in the upper hemisphere of the boulder, with some possible clustering evident in the center of the boulder. There is notably no visible clustering in the vicinity of the "dimple" on the northwest-facing side of the boulder. In the future, we hope to compare this location data with field data of macro-crack locations (Eppes et al., 2011) and with numerical models of the locations of maximum stress accrued in a diurnally heated boulder (Hallet et al., 2012). Future 4-D spatial/temporal statistical analysis of the data will also allow us to determine if events forming under varying temperature and/or strain conditions are initiated in different locations within the test specimen.

\section{Conclusions}

This paper provides a sample of the robust data that has been collected by the complex instrumentation configuration described herein. To date, all data appears reasonable in trend and magnitude and is on par with other studies that involve the measurement of rock surface temperature, strain, and moisture. This system appears to be accurately recording the environmental conditions and fracturing of the boulder. 
Based on the data that has been collected on this test specimen (in addition to previous and ongoing test specimens), the $\mathrm{AE}$ events represent mechanical deformation in the test boulder that is due to fracturing commonly experienced by granite boulders exposed to diurnal conditions. While the calculated locations of these AE events have a relatively high margin of spatial error, relevant information from these data has been collected and will be utilized to facilitate the ongoing spatial analysis effort. At a minimum, it has been shown that fracturing of the boulder can be monitored simultaneously with the concurrent surface and ambient conditions before, during, and after the time of fracturing with high spatial and temporal resolution.

Since the completion of the work described herein, a third test specimen was instrumented and deployed during the summer of 2011 for a two year monitoring period in New Mexico to monitor conditions in a desert environment over a longer time duration. These data have also been utilized by participating colleagues (e.g., Hallet et al., 2012) to provide accurate inputs and testing of numerical models of stress states of boulders exposed to natural diurnal conditions. Macrocrack field data continues to be collected around the globe (e.g., Eppes et al., 2011). The combination of an extensive instrumentation monitoring program like this one in conjunction with field data and numerical modeling represents an unequivocal step to deconvolving the mechanical processes that lead to non-tectonic rock fracture for rocks that are subaerially exposed on Earth's surface.

Acknowledgements. This research was funded by two National Science Foundation (NSF) awards (EAR-0844335 and EAR0705277). The authors would like to thank Jim Conrad and Andrew Willis of UNC Charlotte for their support throughout this project. We would also like to thank the Redlair Research Preserve for the use of their land and Doug Shafer for use of his property during a previous field study, as well as Bernard Hallet, Peter Mackenzie and Les McFadden for fruitful discussions and field visits to our deployed rocks.

Edited by: L. Eppelbaum

\section{References}

Amit, R., Gerson, R., and Yaalon, D. H.: Stages and rate of the gravel shattering process by salts in desert Reg soils, Geoderma, 57, 295-324, 1993.

Blackwelder, E. B.: The insolation hypothesis of rock weathering, Am. J. Sci., 226, 1324-1400, 1933.

Eberhardt, E., Stead, D., Stimpson, B., and Read, R. S.: Identifying fracture initiation and propagation thresholds in brittle rock, Can. Geotech. J., 35, 222-233, 1998.

Eppes, M. C., McFadden, L., Wegmann, K., and Scuderi, L.: Fractures in desert pavement rocks: further insights into mechanical weathering by directional solar heating, Geomorphology, 123, 97-108, 2010.
Eppes, M. C., Aldred, J., Aquino, K., Deal, R., Garbini, J., Swami, S., Tuttle, Al., and Xanthos, G.: Documentation of preferential orientations of cracks in boulder fields of temperate climates: Further evidence for the influence of directional insolation in physical weathering, vol. 43, Geological Society of America Annual Meeting, October 2011, Minneapolis, MN, Abstracts with Program, p. 252, 2011.

Eppes, M. C., Warren, K., Hinson, E., and Dash, L.: Physical weathering by insolation: comparison of year long, per-minute observation so temperature, strain and cracking in granite boulders in a temperate pasture and semiarid desert, North Carolina and New Mexico, Vol. 44, Geological Society of America Abstracts with Programs, p. 145, 2012.

Garbini, J.: Instrumentation and analysis of the diurnal processes affecting a natural boulder exposed to a natural environment, UNC Charlotte Thesis, Charlotte, USA, p. 148, 2009.

Girard, L., Beutel, J., Gruber, S., Hunziker, J., Lim, R., and Weber, S.: A custom acoustic emission monitoring system for harsh environments: application to freezing-induced damage in alpine rock walls, Geosci. Instrum. Method. Data Syst., 1, 155-167, doi:10.5194/gi-1-155-2012, 2012.

Grosse, C. and Ohtsu, M.: Acoustic Emission Testing, in: Technology \& Engineering, Springer Verlag Berlin Heidelberg Germany, 1-396, 2008.

Hall, K.: The role of thermal stress fatigue in the breakdown of rock in cold regions, Geomorphology, 31, 47-63, 1999.

Hall, K. and André, M. F.: Rock thermal data at the grain scale: applicability to granular disintegration in cold environments, Earth Surf. Proc. Land., 28, 823-836, 2003.

Hall, K. and Hall, A.: Weathering by wetting and drying: some experimental results, Earth Surf. Proc. Land., 21, 365-376, 1996.

Hallet, B., Walder, J., and Stubbs, C. W.: Weathering by segregation ice growth in microfractures at sustained sub-zero temperatures: verification from an experimental study using acoustic emissions, Permafrost Periglac., 2, 283-300, 1991.

Hallet, B., Mackenzie-Helnwein, P., Shi, J., and Eppes, M.: Are thermal stresses in rocks exposed to the sun sufficient to break them? Yes, Vol. 44, No. 7, Geological Society of America Abstracts with Programs, p. 145, 2012.

Huang, M., Jiang, L., Liaw, P., Brooks, C., Seeley, R., and Klarstrom, D.: Using Acoustic Emission in Fatigue and Fracture Materials Research, J. Mech., 50, http://www.tms.org/ pubs/journals/JOM/9811/Huang/Huang-9811.html (last access: November 2013), 1998.

Khair, A.: Acoustic emission pattern; an indicator of mode of failure in geologic materials as affected by their natural imperfections, Acoustic Emission/Microseismic Activity in Geologic Structures and Materials, proceedings of the third conference 1981, University Park PA, USA, 45-66, 1984.

Lei, X., Kusunose, K., Rao, M., Nishizawa, O., and Satoh, T.: Quasi-static fault growth and fracturing in homogeneous brittle rock under triaxial compression using acoustic emission monitoring, J. Geophys. Res., 105, 6127-6139, 2000.

Lockner, D. A., Byerlee, J. D., Kuskenko, V., Ponomarev, A., and Sidorin, A.: Quasi-static fault growth and shear fracture energy in granite, Nature, 350, 39-42, doi:10.1038/350039a0, 1991. 
McFadden, L. D., Eppes, M. C., Gillespie, A. R., and Hallet, B.: Physical weathering in arid landscapes due to diurnal variation in the direction of solar heating, Geol. Soc. Am. Bull., 110, 161173, 2005.

McKay, C. P., Molaro, J. L., and Marinova, M. M.: High-frequency rock temperature data from hyper-arid desert environments in the Atacama and the Antarctic Dry Valleys and implications for rock weathering, Geomorphology, 110, 182-187, 2009.

Molaro, J. L. and McKay, C. P.: Processes controlling rapid temperature variations on rock surfaces, Earth Surf. Proc. Land., 35, 501-507, 2010.

Moores, J. E., Pelletier, J. T., and Smith, P. H.: Fracture propagation by differential insolation on desert surface clasts, Geomorphology, 102, 472-481, 2008.

Morton, D. M. and Miller, F. K.: Preliminary Geologic Map of the San Bernardino $30^{\prime} \times 60^{\prime}$ quadrangle, California, US Geological Survey Open-File report 03-293, US Geological Survey, Menlo Park, California, 2003.

Nicholson, D. T.: Pore properties as indicators of breakdown mechanisms in experimentally weathered limestones, Earth Surf. Proc. Land., 26, 819-838, 2001.

Pollock, A. A.: Acoustic Emission Inspection, Metals Handbook, 9th Edn., Vol. 17, ASME International, Ohio, USA, 278-294, 1989.

Rao, N., Murthy, G., and Raju, N.: Characterization of micro and macro-fractures in rocks by acoustic emission, ASTM Special Technical Publication 1353, American Society for Testing and Materials, West Conshohocken, PA, 141-155, 1999.
Richter, D. and Simmons, G.: Thermal expansion behavior of igneous rocks, Int. J. Rock Mech., 11, 403-411, 1974.

Shi, J.: Study of Thermal Stresses in Rocks Due to Diurnal Solar Exposure, MS Thesis, University of Washingtion, Washington, 1-103, 2011.

Tanigawa, Y. and Takeuti, Y.: Three-dimensional thermoelastic treatment in a spherical region and its application to solid sphere due to rotating heat source, Z. Angew. Math. Mech., 63, 317324, 1983.

Turkington, A.: Stone Decay in the Architectural Environment, Geological Society of America Special Publication 390, Geological Society of America, Boulder, CO, USA, p. 62, 2005.

Viles, H. A.: Microclimate and weathering in the central Namib Desert, Geomorphology, 67, 189-209, 2005.

Viles, H. A. and Goudie, A. S.: Rapid salt weathering in the coastal Namib Desert: Implications for landscape development, Geomorphology, 85, 49-62, 2007.

Vishay Micro-Measurements: Strain gage installations with MBond 200 Adhesive, Instruction Bulletin, B-127-14, 1-4, 2005.

Walder, J. and Hallet, B.: A theoretical model of the fracture of rock during freezing, Geol. Soc. Am. Bull., 96, 336-346, 1985.

Wegmann, M. and Gudmundsson, G. H.: Thermally induced temporal strain variations in rock walls observed at subzero temperatures, Lect. Notes Phys., 533, 511-518, 1999. 